\title{
Identification of Minimal Promoter and Genetic Variants of Kruppel-like Factor 11 Gene and Association Analysis with Type 2 Diabetes in Japanese
}

\author{
EIJI KURODA*, YUKIO HORIKAWA*,**, MAYUMI ENYA*, NAOHISA ODA***, EIJI SUZUKI*, \\ KATSUMI IIZUKA** AND JUN TAKEDA* \\ *Department of Diabetes and Endocrinology Division of Molecule and Structure, Gifu University School of Medicine, Gifu, Japan \\ **Laboratory of Medical Genomics, Biosignal Genome Resource Center, Institute for Molecular and Cellular Regulation, Gunma \\ University, Maebashi, Japan \\ ***Department of Internal Medicine, Fujita Health University School of Medicine, Aichi, Japan
}

\begin{abstract}
Genetic analysis of the KLF11 gene revealed two rare variants, A347S and T220M, segregating in families with early-onset type 2 diabetes, and one frequent polymorphic Q62R variant significantly associated with type 2 diabetes in Northern Europeans. Furthermore, it has been reported that over-expression of KLF11 has a deleterious effect on insulin promoter activity. Thus, an altered expression level of KLF11 may contribute to the occurrence of type 2 diabetes. To investigate the contribution of KLF11 to type 2 diabetes in Japanese, we surveyed the 5' flanking region of KLF11 by reporter assay and identified the minimal promoter region of the gene. The promoter region from -250 to $+162 \mathrm{bp}$ including five Sp1 binding sites showed basal promoter activity both in MIN6-m9 and HepG2 cells. We also examined the entire region of KLF11 to detect genetic variants. A total of 19 polymorphisms, six of which are novel, were identified, but none of them showed association with the occurrence of type 2 diabetes. Two of the identified polymorphisms, R29Q and S124F, are novel coding variants. Functional analyses of these variants were performed, and similarly reduced effects on transcriptional activities of insulin, catalase1, and the Smad7 gene were found. We conclude that variants of KLF11 are not a major factor in the occurrence of type 2 diabetes in Japanese. The promoter region of KLF11 identified in the present study should be useful in further elucidation of the transcriptional regulation mechanism of the gene and genetic analyses of type 2 diabetes.
\end{abstract}

Key words: KLF11, SNP, association study, promoter, type 2 diabetes

(Endocrine Journal 56: 275-286, 2009)

KRUPPEL-LIKE transcription factor (KLF)11 (also known as TIEG2) is a member of the Sp1-like transcription factor family, which is defined by the presence of three conserved DNA-binding C-terminal zinc finger domains and variant $\mathrm{N}$-terminal domains [1-4]. In contrast with $\mathrm{Sp} 1$, one of the best-characterized transcriptional activators, KLF11 behaves as a potent transcriptional repressor. KLF/Sp1-like transcription

Received: October 21, 2008

Accepted: December 12, 2008

Correspondence to: Yukio HORIKAWA, M.D., Ph.D., Department of Diabetes and Endocrinology, Division of Molecule and Structure, Gifu University School of Medicine, Gifu, Japan regulation may participate in many aspects of cellular function, including cell proliferation, apoptosis, differentiation, and neoplastic transformation [5-8].

The KLF11 gene is located at chromosome $2 \mathrm{p} 25$ [9], and is ubiquitously expressed in human tissues with an abundance in pancreas and muscle [4]. KLF11 has elicited significant attention due to its role as a negative regulator of exocrine cell growth by decreasing growth and increasing apoptosis via a mechanism that involves down-regulation of the oxidative stress genes SOD2 and catalase1 [10], which also are expressed in pancreatic islets, and an increased susceptibility to oxidative insult [11]. The Smad-regulated transcriptional pathway plays a central role in TGF- $\beta$ 
induced cell growth inhibition [12]. Smad signaling activity is potentiated by KLF11 in normal epithelial cell lines through termination of the negative feedback loop imposed by Smad7, which requires binding to GC-rich promoter boxes of the Smad7 promoter [13], and the TGF- $\beta$ signaling pathway is a major regulator of endocrine cell fate [14-16].

The role of KLF11 within the endocrine pancreas remains to be elucidated. Recently, Neve et al. reported that KLF11 binds to the insulin promoter and upregulates its activity in beta-TC3 cells. Genetic analysis of KLF11 revealed two rare variants (Ala347Ser and Thr220Met) that segregate with diabetes in families with early-onset type 2 diabetes (T2DM) and significantly impair its transcriptional activity [17]. On the other hand, Niu et al. reported that over-expression of hKLF11 inhibits the activity of human insulin promoter in INS-1E and beta-TC3 cells in a dosedependent and glucose-independent manner [18]. Furthermore, it has been reported that a KLF11 promoter variant has a deleterious effect on insulin sensitivity via STAT3-mediated up-regulation of KLF11 [19]. Thus, an altered expression level of KLF11 may contribute to the occurrence of type 2 diabetes.

In this study, we surveyed the 5' flanking region of KLF11 and identified the minimal promoter region of the gene, which should be useful in further genetic and functional analyses of type 2 diabetes. We also examined all of the regions of KLF11 in twelve Japanese subjects to detect genetic variants, evaluated the pattern of linkage disequilibrium to infer haplotypes in the gene, and performed association studies with type 2 diabetes patients.

\section{Material and Methods}

\section{Subjects}

A total of 182 Japanese subjects with clinical diagnosis of early-onset type 2 diabetes (70 males and 112 females; onset age $11.9 \pm 3.1 \mathrm{yr}$, BMI, $23.9 \pm 6.2 \mathrm{~kg} /$ $\mathrm{m}^{2}$; onset $\mathrm{HbAlc} 8.8 \pm 3.1 \%$, HbAlc $7.1 \pm 2.3 \%$ ) were screened for mutations by direct sequencing of PCR products. Patients with glutamic acid decarboxylase (GAD) antibodies and other types of diabetes were excluded on the basis of clinical data.

A total of 553 Japanese patients with late-onset T2DM [310 males and 243 females; age at testing,
$61.1 \pm 10.6 \mathrm{yr} ;$ BMI, $23.9 \pm 4.1 \mathrm{~kg} / \mathrm{m}^{2} ;$ glycosylated hemoglobin (HbA1c), $7.7 \pm 3.5 \%$ ] and 563 controls (224 males and 339 females; age at testing $67.4 \pm 6.0$ yr; BMI, $22.9 \pm 2.9 \mathrm{~kg} / \mathrm{m}^{2}$; HbA1c, $5.0 \pm 0.4 \%$ ) were examined for association study. The diagnosis of T2DM was based on medical records or $75 \mathrm{~g}$ oral glucose tolerance test according to the criteria of the Japan diabetes Society [20]. Informed consent was obtained from all of the diabetic subjects and volunteer controls. The study was approved by the ethics committee of Gifu University.

\section{SNP identification in KLF11}

Genomic DNA was extracted from samples of whole blood using QIAamp DNA blood kit (QIAGEN, Hilden, Germany) according to the manufacturer's instructions. Twelve of the random control samples (24 alleles) were used to detect SNPs in KLF11. Primers for PCR experiments were designed by Primer3 (available from http://www.genome.wi.mit.edu/cgibin/primer/preimer3 www.cgi) on the basis of the genomic contig sequence (GenBank ID: NT_005334.15, nt 5016199-5029771 bp) of the KLF11 region. The mixture for PCR was $20 \mu \mathrm{l}$ in $10 \mathrm{ng}$ template DNA, $0.5 \mathrm{mM}$ of each dNTP, $2.5 \mathrm{pmol}$ of each forward and reverse primer, $0.5 \mathrm{U}$ ExTaq polymerase (Takara, Kyoto, Japan), and $2 \mu \mathrm{l}$ of $10 \times$ PCR buffer or $0.4 \mathrm{U}$ KOD FX (TOYOBO, OSAKA, JAPAN) and $10 \mu \mathrm{l}$ of $2 \times$ PCR buffer for KOD FX. The reaction conditions with Ex Taq polymerase were an initial denaturation step of $94^{\circ} \mathrm{C}$ for $1 \mathrm{~min}$ and a subsequent 35 cycles of reaction at $94^{\circ} \mathrm{C}$ for $30 \mathrm{sec}, 60^{\circ} \mathrm{C}$ for $30 \mathrm{sec}$, and $72^{\circ} \mathrm{C}$ for $1 \mathrm{~min}$; the reaction conditions with KOD FX were an initial denaturation step of $94^{\circ} \mathrm{C}$ for $2 \mathrm{~min}$ and a subsequent 35 cycles of reaction at $98^{\circ} \mathrm{C}$ for $10 \mathrm{sec}$, $60^{\circ} \mathrm{C}$ for $30 \mathrm{sec}$, and $68^{\circ} \mathrm{C}$ for $1 \mathrm{~min}$. After purification, each PCR product was subjected to cycle sequencing with BigDye Terminator cycle sequencing FS (Applied Biosystems, Foster City, CA) using each forward and reverse primer. Reaction products were purified by ethanol precipitation and sequenced by ABI PRISM 3130 sequencer (Applied Biosystems).

\section{Estimation of haplotype frequencies and evaluation of pattern of LD in KLF11}

Haplotypes comprising tag SNPs and haplogenotypes were inferred by the expectation-maximization 
method by Haploview (http://www.broad.mit.edu/ personal/jcbarret/haploview) and PHASE 2.1.1 (http:// www.stat.washington.edu/stephens/software.html), respectively.

\section{Mutation screening and genotyping of frequent polymorphisms in KLF11}

We examined all of the coding regions and the putative promoter region of KLF11 in 182 early-onset T2DM, 96 of the 553 late-onset T2DM patients (56 males and 40 females; age $63.2 \pm 11.0 \mathrm{yr}$, BMI, $\left.24.5 \pm 5.4 \mathrm{~kg} / \mathrm{m}^{2} ; \mathrm{HbA} 1 \mathrm{c} 7.9 \pm 1.6 \%\right)$ and 96 of 563 control subjects (35 males and 61 females; age $67.6 \pm 5.8$ age yr; BMI, $22.8 \pm 2.8 \mathrm{~kg} / \mathrm{m}^{2} ; \mathrm{HbA} 1 \mathrm{c}$ $4.9 \pm 0.3 \%$ ). We performed an additional screening for R29Q and S124F mutations in all late-onset T2DM patients and controls.

Association study was performed for tag SNPs (SNP2, -3, -5, -6) in the promoter region with 96 subjects each from 552 late-onset T2DM and 563 controls by direct sequencing. As it was extremely difficult to amplify the promoter region due to its high GC content, only 96 subjects from each group were examined. Association study for tag SNP 13 (rs6432053) was performed in the 552 late-onset T2DM patients and 563 controls by TaqMan assay (Applied Biosystems) on an ABI PRISM 7900HT sequence detector (AppliedBiosystems). Thermal cycling conditions followed the manufacturer's instructions.

\section{Cell lines}

MIN6-m9 cells were maintained in DMEM containing $25 \mathrm{mM}$ glucose, $10 \%$ heat-inactivated FBS, $50 \mathrm{mM}$ 2-mercaptoethanol, $100 \mathrm{mg} / \mathrm{l}$ streptomycin sulfate, and $60.5 \mathrm{mg} / \mathrm{l}$ penicillin $\mathrm{G}$ under a humidified condition of $5 \% \mathrm{CO} 2-95 \%$ air at $37^{\circ} \mathrm{C}$ [21]. HepG2 cells were maintained in DMEM supplemented with $10 \%$ heat-inactivated FBS, $100 \mathrm{mg} / 1$ streptomycin sulfate, and $60.5 \mathrm{mg} / 1$ penicillin $\mathrm{G}$ under a humidified condition of $5 \% \mathrm{CO} 2-95 \%$ air at $37^{\circ} \mathrm{C}$.

\section{Identification of the minimal promoter region of human KLF11}

To establish the promoter activity of the 5 ' flanking region of KLF11, we designed luciferase expression vectors including a series of 5' deletion fragments.
Three different length fragments, from -1389 to $+162 \mathrm{bp},-896$ to $+162 \mathrm{bp}$ and -250 to +162 bp relative to the transcription start site, were prepared by PCR and inserted into the firefly luciferase reporter vector, pGL4.12-Basic (Promega, Madison, WI). The MIN6-m9 cells or HepG2 cells were seeded in 6-well culture plates. The confluency was $50-70 \%$ at the time of transfection. The reporter constructs (500 ng) were transfected to cells by using a ExGEN 500 in vitro Transfection Reagent (Fermentas, St. Leon-Rot, Germany). Transcriptional activity was normalized with a co-transfected control thymidine kinase (TK)regulated Renilla luciferase vector, pRL-TK $17 \mathrm{ng}$ (Promega). Transactivation activity was measured using Dual-Luciferase Reporter Assay system (Promega).

\section{Subcloning of human KLF11 and variants}

A cDNA identical to KLF11 was retrieved from a human islet cDNA library and subcloned in pENTR/ D-TOPO (Invitrogen, Carlsbad, CA) after amplification with Pfu (Stratagene, La Jolla, CA) and transferred for expression to pcDNA6.2-DEST (Invitrogen). The R29Q and S124F mutations were introduced by site-directed mutagenesis (Stratagene, La Jolla, CA) with $\mathrm{pENTR/d-TOPO}$ wild-type KLF11 as template and confirmed by sequencing.

\section{Functional analysis of KLF11 mutant proteins}

The reporter constructs for insulin, catalase1, or Smad7 promoter-pGL3 were prepared by cloning the human insulin $(-365 \sim+40$ bp) [18], catalase1 ( -734 $\sim+11$ bp) [10], or Smad7 (-836 +74 bp) [11] gene promoter into the pGL3-Basic vector (Promega, Madison, WI $)$. The MIN6-m9 cells $\left(1 \times 10^{5}\right.$ cells/well $)$ were seeded in 6 -well culture plates. The confluency was $50-70 \%$ at the time of transfection. Constructed plasmids, pcDNA6.2 wild-type hKLF11, or pcDNA6.2 mutant-type hKLF11 and each reporter construct were transfected to MIN6-m9 cells using ExGEN 500 in vitro Transfection Reagent (Fermentas, St. Leon-Rot, Germany). Transcriptional activity was normalized with a co-transfected control thymidine kinase (TK)regulated Renilla luciferase vector, pRL-TK (Promega). Transactivation activity was measured using Dual-Luciferase Reporter Assay system (Promega). 


\section{Statistical analyses}

Statistical difference in allele frequencies between late-onset T2DM and control subjects was assessed by $\chi^{2}$ test or logistic regression analysis adjusted for relevant covariates, and other categorical clinical variables were compared using $t$ test. Statistical analysis was performed with StatView 5.0 software (SAS Institute, Inc., Cary, NC). Comparison of estimated haplotype frequencies was performed by conducting separate one-degree of freedom tests for a series of $2 \times 2$ contingency tables testing the frequency of each specific haplotype vs all others between cases and controls, and omnibus testing of differences in haplotype frequency profiles between the cases and controls (statistical significance assessed empirically via permutation testing with PHASE 2.1.1 software). The present study had about $33-50 \%$ power to detect an OR of 1.20 when the frequency of a risk allele was $10-20 \%$ and $P$-value was less than 0.05 under a multiplicative model with 553 patients and 563 controls, while it had only 10 $13 \%$ power to detect an OR of 1.20 when the frequen- cy of a risk allele was $10-20 \%$ and $P$-value was less than 0.05 under a multiplicative model with 96 each of patients and controls.

\section{Results}

\section{Identification of polymorphisms in KLF11}

Twelve of the random controls were examined to detect genetic variations in the entire region of KLF11 including all 4 exons. A total of 17 polymorphisms, four of which are novel, were found as shown in Table 1 ; the locations of these polymorphisms are shown in Fig. 1 in relation to the genomic structure of KLF11. The additional two variants, R29Q and S124F were found by screening a large number of type 2 diabetic patients. Two coding variants, R29Q and S124F, are novel. In the $1552 \mathrm{bp}$ (from -1389 to $+162 \mathrm{bp}$ ) region of the KLF11 promoter, a total of seven polymorphisms including four novel ones were identified.

Table 1. Polymorphisms identified in KLF11 region in this study

\begin{tabular}{|c|c|c|c|c|c|}
\hline $\begin{array}{l}\text { SNP } \\
\text { No. }\end{array}$ & $\begin{array}{l}\text { Position } \\
\text { genome }\end{array}$ & $\mathrm{db}$ SNP ID & Variation & Location & $\begin{array}{l}\text { Frequencies of } \\
\text { minor allele }\end{array}$ \\
\hline 1 & -1348 & rs 4669520 & $\mathrm{G}>\mathrm{A}$ & 5' flanking & 0.134 \\
\hline 2 & -1025 & rs35035311 & ins $\mathrm{G}$ & 5 ' flanking & 0.132 \\
\hline \multirow[t]{3}{*}{3} & -530 & novel & $(\mathrm{CCG})^{*}$ & 5' flanking & 4: 0.744 \\
\hline & & & & & 2: 0.139 \\
\hline & & & & & 5: 0.117 \\
\hline 4 & -499 & novel & del (CCCCGCCG) & 5' flanking & 0.114 \\
\hline 5 & -446 & novel & del/ins (CCCCCTCCG) & 5' flanking & 0.276 \\
\hline 6 & -278 & novel & del/ins (GGCCGGGCACG) & 5' flanking & 0.138 \\
\hline 7 & -86 & & del/ins (GCC) & 5' UTR & 0.128 \\
\hline 8 & 1467 & rs6717092 & $\mathrm{C}>\mathrm{G}$ & Intron 1 & 0.136 \\
\hline 9 & 2477 & novel & G>A (R29Q) & Exon2 & n.d \\
\hline 10 & 3992 & novel & $\mathrm{C}>\mathrm{A}(\mathrm{S} 124 \mathrm{~F})$ & Exon3 & n.d \\
\hline 11 & 4806 & rs11687357 & $\mathrm{T}>\mathrm{A}(\mathrm{V} 395 \mathrm{~V})$ & Exon3 & 0.133 \\
\hline 12 & 5856 & rs6432052 & $\mathrm{C}>\mathrm{T}$ & Intron 3 & 0.129 \\
\hline 13 & 5992 & rs6432053 & $\mathrm{T}>\mathrm{C}$ & Intron 3 & 0.268 \\
\hline 14 & 6272 & rs6721191 & $\mathrm{G}>\mathrm{A}$ & Intron 3 & 0.128 \\
\hline 15 & 6741 & rs4614909 & $\mathrm{T}>\mathrm{A}$ & Intron 3 & 0.263 \\
\hline 16 & 8199 & rs2487 & $\mathrm{T}>\mathrm{C}$ & Intron 3 & 0.135 \\
\hline 17 & 10349 & rs4669522 & $\mathrm{C}>\mathrm{T}$ & 3' UTR & 0.145 \\
\hline 18 & 10644 & rs7632 & $\mathrm{C}>\mathrm{T}$ & 3' UTR & 0.274 \\
\hline 19 & 11224 & rs6432055 & $\mathrm{C}>\mathrm{T}$ & 3' flanking & 0.259 \\
\hline
\end{tabular}

*Triallelic variant with 2, 4, 5 CCG repeats. The nucleotide indicates the location of the SNP relative to the A of ATG of the initiator Met of KLF11 (GenBank No. NT_005334.15). The frequencies of minor alleles in this table are observed in 96 random control samples except SNP 9, and 10. n.d; not detected. 


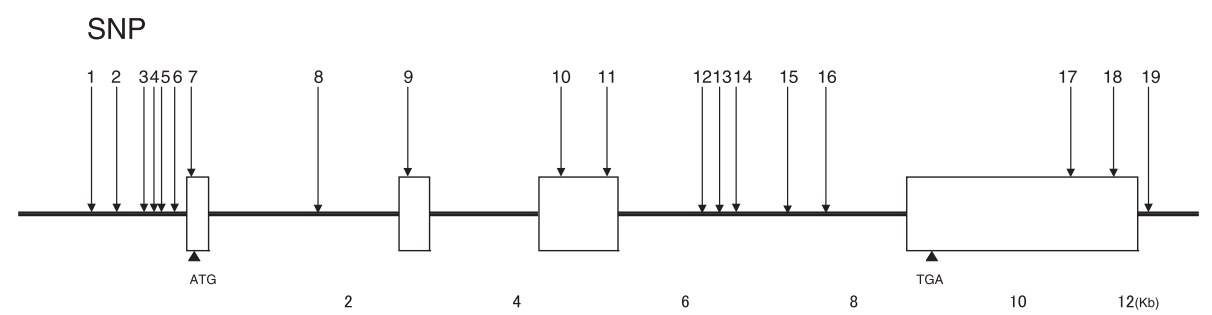

Fig. 1. Polymorphisms of KLF11 identified in this study. The locations of the polymorphisms described in the text are shown. Nucleotide indicates the location of the SNP relative to the A of ATG of the initiator Met of KLF11.

Table 2. Frequencies of coding SNPs in KLF11 in controls and in patients with T2DM

\begin{tabular}{cccccccc}
\hline $\begin{array}{c}\text { SNP } \\
\text { No. }\end{array}$ & $\begin{array}{c}\text { Position } \\
\text { genome }\end{array}$ & db SNP ID & $\begin{array}{c}\text { Nucleotide } \\
\text { change }\end{array}$ & Exon & $\begin{array}{c}\text { Controls } \\
(\mathrm{n}=563)\end{array}$ & $\begin{array}{c}\text { Late-onset T2DM } \\
(\mathrm{n}=553)\end{array}$ & $\begin{array}{c}\text { Early-onset T2DM } \\
(\mathrm{n}=182)\end{array}$ \\
\hline 9 & 2477 & novel & G>A (R29Q) & 2 & 1 & 3 & 2 \\
10 & 3922 & novel & C $>$ A (S124F) & 3 & 0 & 0 & 1 \\
11 & 4806 & rs11687357 & T>A (V395V) & 3 & $26(\mathrm{n}=96)$ & $21(\mathrm{n}=96)$ & 56 \\
\hline
\end{tabular}

The nucleotide indicates the location of the SNP relative to the A of ATG of initiator Met of KLF11

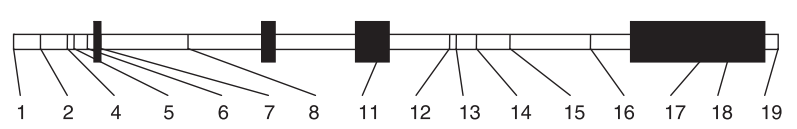

(A)

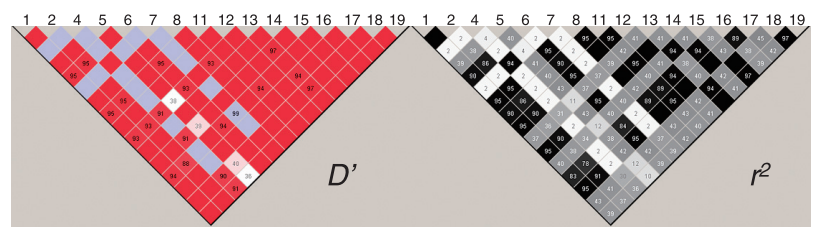

Fig. 2. Pairwise LD of $K L F 11$ evaluated by $D^{\prime}$ and $r^{2}$. The panel shows a Haploview representation of LD $\left(D^{\prime}\right.$ and $\left.r^{2}\right)$ based on genotyping data with 16 polymorphisms from control subjects $(\mathrm{n}=96)($ A) Pairwise combination with LD of $D^{\prime}=1$ and $\operatorname{LOD} \geq 2, D^{\prime}=1$ and $\operatorname{LOD}<2, D^{\prime}<1$ and $\mathrm{LOD} \geq 2, D^{\prime}<1$ and $\mathrm{LOD}<2$ is shown with red, blue, pink and white. (B) Pairwise combination with LD of $r^{2}=1,0<r^{2}<1, r^{2}=0$ is shown in black, gray and white.

\section{Evaluation of the pattern of LD in KLF11}

Sixteen polymorphisms with frequencies of more than $10 \%$ were used to define haplotypes and to evaluate the pattern of LD. As shown in Fig. 2, the single, large LD block appears in this region. Haplotype combinations were estimated with 96 control subjects. Four major haplotypes comprising tag SNPs (SNP-2, -3, -5, -6, -and -13) were inferred in the entire KLF11 region.

\section{Mutation screening of KLF11 and association study in T2DM patients}

All exons and the putative promoter region $(-1389$ to $+162 \mathrm{bp}$ ) of KLF11 were examined in 182 earlyonset T2DM patients, 96 late-onset T2DM patients, and 96 control subjects. A total of 3 cSNPs (R29Q, S124F and V395V), two of which, R29Q and S124F, are novel, were found (Table 2). R29Q mutation was found in five T2DM ( 3 from late-onset and 2 from early-onset) patients and in one control (Fisher's $P$ value $=0.245) . \mathrm{S} 124 \mathrm{~F}$ mutation was found in one early-onset T2DM patient and was not found in controls. An association study using tag SNPs in T2DM patients was performed, but no association of KLF11 variants with T2DM was found (Table 3A \& B). No haplotypes were found to be susceptible to T2DM by $\chi^{2}$ test. Using permutation testing (100 permutations), no significant differences in haplotype frequencies between control and T2DM were found (Table 4).

\section{Functional analysis of KLF11 mutant proteins}

The results of alignment by CLUSTALW show that R29 of KLF11 is conserved among human, mouse, and rat, while S124 is not conserved (Fig. 3). The transcriptional activity of the R29Q and S124F mutants of KLF11 were therefore compared with that of wild type 
Table 3A. Association study using tag SNPs in KLF11 in patients with late-onset T2DM and controls

\begin{tabular}{|c|c|c|c|c|c|c|c|c|c|c|c|c|c|c|}
\hline \multirow[t]{2}{*}{ SNP } & & \multicolumn{2}{|c|}{$\begin{array}{l}\text { Frequencies of } \\
\text { genotype }\end{array}$} & & \multicolumn{2}{|c|}{$\begin{array}{l}\text { Frequencies of } \\
\text { alleles }\end{array}$} & \multicolumn{2}{|c|}{ allele } & \multicolumn{2}{|c|}{ genotype } & \multicolumn{2}{|c|}{ dominant } & \multicolumn{2}{|c|}{ recessive } \\
\hline & & Control & $\mathrm{T} 2 \mathrm{DM}$ & & Control & $\mathrm{T} 2 \mathrm{DM}$ & $\chi^{2}$ & $P$ & $\chi^{2}$ & $P$ & $\chi^{2}$ & $P$ & $\chi^{2}$ & $P$ \\
\hline \multirow[t]{3}{*}{2} & $\mathrm{~W} / \mathrm{W}$ & 0.747 & 0.773 & W & 0.868 & 0.882 & 0.159 & 0.689 & 0.237 & 0.888 & 0.208 & 0.647 & 0.006 & 0.936 \\
\hline & W/M & 0.242 & 0.214 & M & 0.132 & 0.117 & & & & & & & & \\
\hline & $\mathrm{M} / \mathrm{M}$ & 0.01 & 0.011 & & & & & & & & & & & \\
\hline \multirow[t]{3}{*}{5} & $\mathrm{~W} / \mathrm{W}$ & 0.564 & 0.492 & W & 0.724 & 0.725 & 0.0003 & 0.984 & 4.81 & 0.09 & 0.755 & 0.384 & 2.684 & 0.101 \\
\hline & $\mathrm{W} / \mathrm{M}$ & 0.320 & 0.464 & M & 0.276 & 0.274 & & & & & & & & \\
\hline & $\mathrm{M} / \mathrm{M}$ & 0.115 & 0.042 & & & & & & & & & & & \\
\hline \multirow[t]{3}{*}{6} & $\mathrm{~W} / \mathrm{W}$ & 0.734 & 0.732 & W & 0.861 & 0.854 & 0.036 & 0.848 & 0.451 & 0.797 & 0.0005 & 0.982 & 0.436 & 0.508 \\
\hline & $\mathrm{W} / \mathrm{M}$ & 0.255 & 0.244 & M & 0.138 & 0.145 & & & & & & & & \\
\hline & $\mathrm{M} / \mathrm{M}$ & 0.01 & 0.023 & & & & & & & & & & & \\
\hline \multirow[t]{3}{*}{13} & $\mathrm{~W} / \mathrm{W}$ & 0.486 & 0.505 & W & 0.707 & 0.698 & 0.224 & 0.636 & 0.517 & 0.772 & 0.042 & 0.839 & 0.517 & 0.472 \\
\hline & $\mathrm{W} / \mathrm{M}$ & 0.418 & 0.415 & M & 0.293 & 0.302 & & & & & & & & \\
\hline & $\mathrm{M} / \mathrm{M}$ & 0.094 & 0.078 & & & & & & & & & & & \\
\hline
\end{tabular}

Association study was performed for the SNPs (SNP2, 5, and 6) in the promoter region with 96 subjects each from 553 T2DM and 563 controls by direct sequencing, and for SNP (SNP13) in the 553 T2DM patients and 563 controls by TaqMan assay. M, Mutant; W, wild type.

Table 3B. Association study using tag SNPs in KLF11 in patients with late-onset T2DM and controls

\begin{tabular}{|c|c|c|c|c|c|c|}
\hline \multirow{2}{*}{ SNP3 } & \multicolumn{6}{|c|}{ Frequencies of genotype } \\
\hline & 11 & 12 & 13 & 22 & 23 & 33 \\
\hline Control & 0.515 & 0.252 & 0.178 & 0.021 & 0.021 & 0.010 \\
\hline T2DM & 0.559 & 0.178 & 0.166 & 0 & 0.071 & 0.023 \\
\hline \multirow{2}{*}{ SNP3 } & \multicolumn{3}{|c|}{ Frequencies of allele } & \multirow{2}{*}{$P^{* 2}$} & & \\
\hline & 1 & 2 & 3 & & & \\
\hline Control & 0.731 & 0.157 & 0.110 & 0.491 & & \\
\hline T2DM & 0.732 & 0.125 & 0.142 & & & \\
\hline \multirow{2}{*}{ SNP3 } & \multicolumn{2}{|c|}{ Frequencies of genotype } & \multirow{2}{*}{$P^{* 3}$} & \multicolumn{2}{|c|}{ Frequencies of genotype } & \multirow{2}{*}{$P^{* 4}$} \\
\hline & 22 & non 22 & & 33 & non 33 & \\
\hline Control & 0.021 & 0.978 & 0.181 & 0.010 & 0.989 & 0.489 \\
\hline T2DM & 0 & 1 & & 0.023 & 0.976 & \\
\hline \multirow{2}{*}{ SNP3 } & \multicolumn{2}{|c|}{ Frequencies of genotype } & \multirow{2}{*}{$P^{* 5}$} & \multicolumn{2}{|c|}{ Frequencies of genotype } & \multirow{2}{*}{$P^{* 6}$} \\
\hline & $22+12+23$ & $11+13+33$ & & $33+13+23$ & $11+12+22$ & \\
\hline Control & 0.294 & 0.705 & 0.502 & 0.210 & 0.789 & 0.418 \\
\hline T2DM & 0.250 & 0.750 & & 0.261 & 0.738 & \\
\hline
\end{tabular}

Association study was performed for SNP3.

Allele 1 indicates 4 CCG repeats. Allele 2 indicates 2 CCG repeats. Allele 3 indicates 5 CCG repeats.

*1 Triallelic varient was analyzed in a $2 \times 6$ contingency table with genotype frequencies.

$* 2$ Triallelic varient was analyzed in a $2 \times 3$ contingency table with allele frequencies.

*3 Analyses in the recessive model of 22 genotype vs. others.

${ }^{* 4}$ Analyses in the recessive model of 33 genotype vs. others.

$* 5$ Analyses in the dominat model of $22+12+23$ genotypes vs. $11+13+33$ genotypes.

*6 Analyses in the dominat model of $33+13+23$ genotypes vs. $11+12+22$ genotypes. 
Table 4. Major haplotypes and its combinations in KLF11 and risk of late-onset T2DM

\begin{tabular}{|c|c|c|c|}
\hline \multirow{2}{*}{$\begin{array}{c}\text { SNP } \\
235613\end{array}$} & \multicolumn{2}{|c|}{ Haplotype frequencies } & \multirow{2}{*}{$P$-value } \\
\hline & Control & $\mathrm{T} 2 \mathrm{DM}$ & \\
\hline 11111 & 0.59 & 0.57 & 0.463 \\
\hline 11211 & 0.127 & 0.125 & 0.504 \\
\hline 13112 & 0.113 & 0.129 & 0.985 \\
\hline 22222 & 0.119 & 0.113 & 0.640 \\
\hline Haplotype combination & Risk (O.R.) & $95 \%$ C.I. & \\
\hline $11111 / 11111$ & 1.29 & $0.71-2.35$ & \\
\hline $11111 / 11211$ & 1.43 & $0.55-3.75$ & \\
\hline $11111 / 13112$ & 0.60 & $0.26-1.36$ & \\
\hline $11111 / 22222$ & 0.75 & $0.32-1.77$ & \\
\hline $11211 / 11211$ & 0.32 & $0.03-3.19$ & \\
\hline $11211 / 13112$ & 2.02 & $0.18-22.75$ & \\
\hline $11211 / 22222$ & 0.19 & $0.02-1.67$ & \\
\hline $13112 / 13112$ & 1.00 & $0.06-16.3$ & \\
\hline $13112 / 22222$ & 6.38 & $0.75-54.13$ & \\
\hline
\end{tabular}

The haplotype frequencies were estimated from the genotype of 96 controls and 96 T2DM subjects. The O.R and 95\% C.I. of each haplotype combination relative to the other haplotype combinations as a group are shown. The numbers 1 and 2 indicate major allele and minor allele (SNP 2, SNP 5, SNP 6, SNP 13). SNP 3; allele 1 indicates 4 CCG repeats, allele 2 indicates 2 CCG repeats, and allele 3 indicates 5 CCG repeats.

(A) $R 29 Q(E x o n 2, G>A)$

MOUSE MHSPGSTGPGDGRAADIMDICESILERKRHDSERSTCSVLEQTDIEAVEALVCMSSWGQR RAT MHSPGSTGPGDARAADIMDICES ILERKRHDSERSTCSILEQTDIEAVEALVCMSSWGQR HUMAN MHTPDFAGPDDARAVDIMDICES ILERKRHDSERSTCSILEQTDMEAVEALVCMSSWGQR **:*. : **. *. **. *************************:*****:****************

\section{(B) $\mathrm{S} 124 \mathrm{~F}($ Exon3, $\mathrm{C}>\mathrm{A})$}

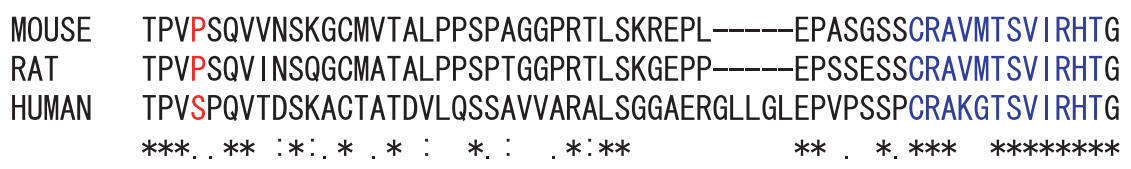

Fig. 3. The results of alignment of KLF11 among human, rat and mouse. A) Red indicates the novel mutation, R29Q, and blue indicates the region of SID. B) Red indicates the novel mutation, S124F, and blue indicates the region of R2. SID: mSin3A interaction domain; R2: transcriptional repression domain * completely conserved,: highly conserved,. moderately conserved.

KLF11. KLF11, catalase1, or Smad7 expression in MIN6-m9 cells was first confirmed, and all of these genes were endogenously expressed in both MIN6-m9 cells (data not shown). Wild-type KLF11 reduced all of these promoter activities to approximately 0.5 -fold. Significantly reduced activity of R29Q mutant repression was found in catalase 1 promoter, and reduced S124F mutant repression activity was found both in insulin and catalase 1 promoter. However, the differ- ences in activity between wild-type and these mutants of KLF11 were very small (Fig. 4).

\section{Identification of the minimal promoter region of human KLF11}

To identify the region essential for basal promoter activity of $K L F 11$, the relative luciferase activity of the three sizes of 5' deletion reporter constructs was evalu- 
(A)

$$
\begin{aligned}
& \square \text { Con } \\
& \text { KLF11 WT } \\
& \square \text { KLF11 R29Q }
\end{aligned}
$$

(B) $\square$ Con$$
\text { KLF11 WT }
$$

$$
\square \text { KLF11 S124F }
$$

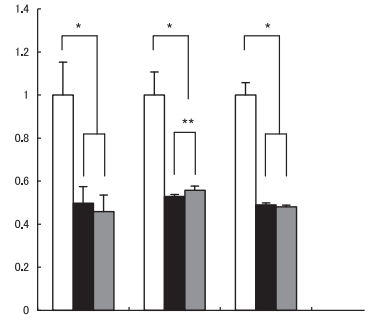

Insulin Catalase1 Smad7

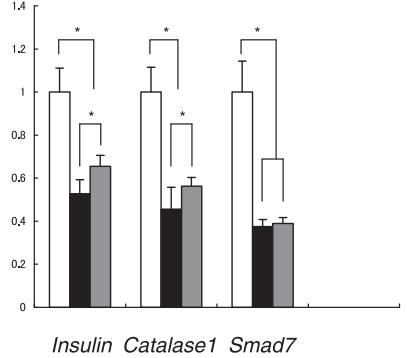

Insulin Catalase1 Smad7
Fig. 4. Transactivation activity of mutant KLF11. Transcription activity with empty vector, wild type, and mutant KLF11 (500 ng) was analyzed by co-transfection assay using reporter vector of Insulin, Catalase-1 and Smad7 promoter-PGL3 (500 ng) and a Renilla luciferase (17 ng) as internal control. (A) The results of R29Q mutant $(n=6)(B)$ The results of S124F mutant $(n=6)$ Data are expressed as means \pm SD.

$* P<0.005, * * P<0.05$ ated. As shown in Fig. 5, the shortest promoter construct comprising each of the four major haplotypes had basal activity both in MIN6-m9 cells and HepG2 cells, suggesting that the basal promoter is involved in the region between -250 and $+162 \mathrm{bp}$. The second longest and longest promoter constructs had stronger activity in HepG2 cells, suggesting that the essential enhancer element for promoter activity of KLF11 is incorporated in the region between -896 and $-250 \mathrm{bp}$, while the second longest and longest promoter constructs had similar activity in MIN6-m9 cells. One of the promoter polymorphisms, SNP-4, is located at the sixth Sp1 binding site from the transcription start site, and is not incorporated in one of the major haplotypes, 1-3-1-1 (Table 4, Fig. 6). A significant difference in promoter activity between this haplotype and the other three major haplotypes was not detected in the promoter assay in MIN6-m9 cells. One of the major haplotypes, 2-2-2-2, showed the highest transcriptional activity with the longest and the second longest constructs $(1.43 \pm 0.046$ fold, $P=0.0064 ; 1.28 \pm 0.018$ fold, $P=0.0069$ ) (Fig. 5).
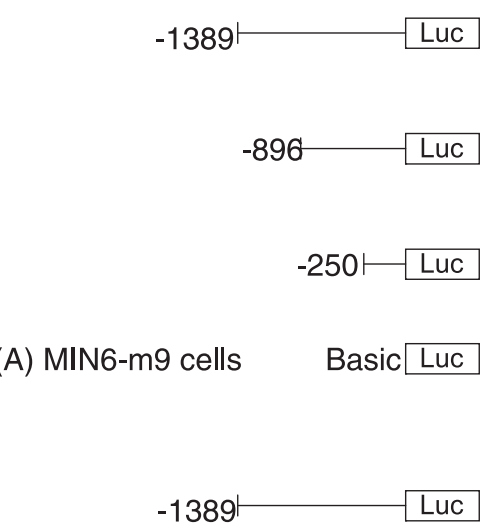

(B) HepG2 cells
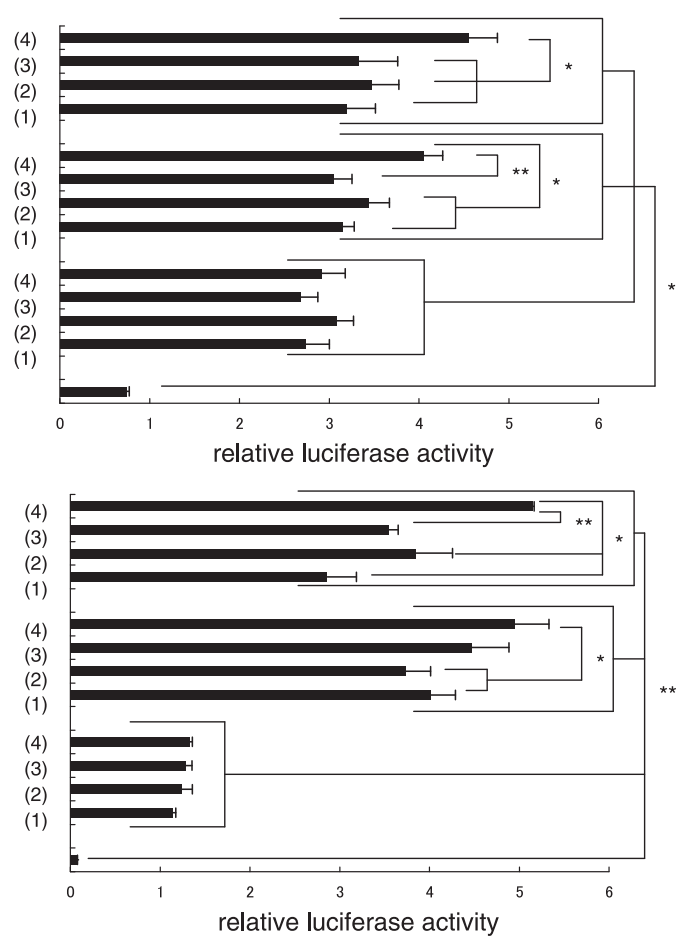

Fig. 5. Identification of KLF11 promoter region using relative luciferase assays. The four haplotypes of the promoter region are indicated by (1) 1-1-1-1 (2) 1-1-2-1 (3) 1-3-1-1 (4) 2-2-2-2. The numerals 1 and 2 indicate major allele and minor allele (SNP 2, SNP 3, SNP 5, SNP 6). SNP 3, allele 1 indicates 4 CCG repeats, allele 2 indicates 2 CCG repeats, allele 3 indicates 5 CCG repeats. (A) The result in MIN6-m9 cells $(n=3)(B)$ The result in HepG2 cells $(n=3)$. Results are expressed as means \pm SD of a representative of experiments performed in triplicate. $* P<0.05, * * P<0.005$ 


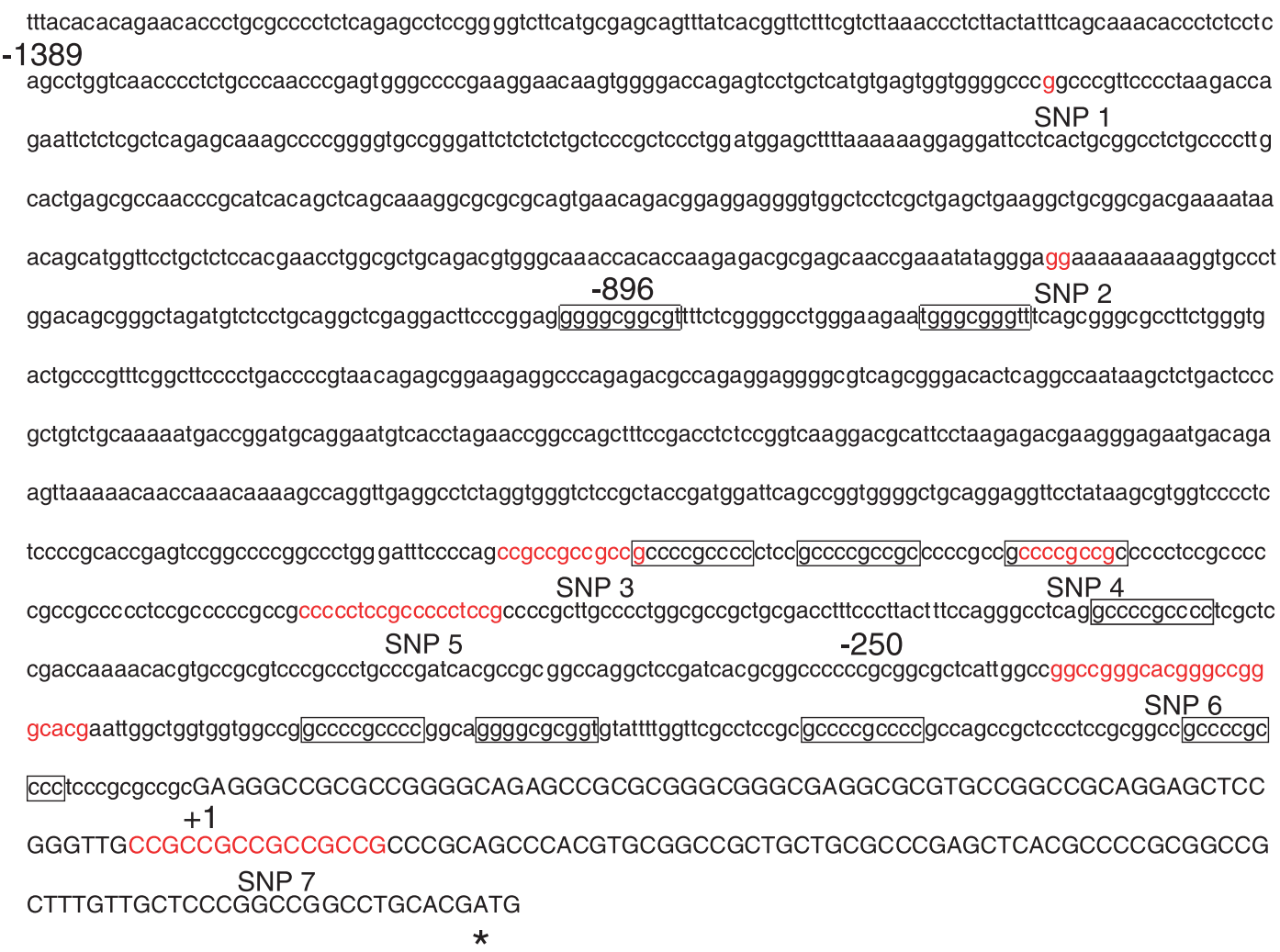

Fig. 6. Nucleotide sequence of the promoter region of KLF11 from transcription start site to -1389 bp of 5 ' flanking region. Consensus sequences for Sp1 are boxed. Red color indicates the sites of polymorphisms. Large characters indicate 5' UTR region of KLF11 and +1 denotes a transcription start site. Asterisk indicates the A of ATG of the initiator Met of KLF11.

\section{Discussion}

Genetic analysis of KLF11 reveals two rare variants, A347S and T220M, which segregate in families with early-onset type 2 diabetes. In addition, analysis of 1,696 type 2 diabetic patients and 1,776 controls found one frequent polymorphic Q62R variant that significantly associates with late-onset type 2 diabetes in North European populations [17]. Florez et al. reported that KLF11 Q62R polymorphism is not associated with late-onset type 2 diabetes in 8,676 subjects of northern-European ancestry, and both A347S and T220M rare variants also are not found [22]. Recently, Ma et al. reported that neither Q62R nor any other common variant in KLF11 was associated with lateonset type 2 diabetes in the Pima population [23]. Normoglycemic R62 carriers showed a significantly decreased plasma insulin level at 60 and 120 min after oral glucose load, leanness, and increased insulin sensitivity [17]. These characteristics clearly differ from those of Caucasian patients with T2DM, which are often caused by impaired insulin action mainly due to obesity. Obesity and insulin resistance are closely associated with type 2 diabetes in Caucasians, while type 2 diabetes in Japanese is characterized primarily by pancreatic beta-cell dysfunction [24, 25]. Thus, KLF11 is a candidate diabetogenic gene in Japanese. Tanahashi et al. reported identification of eight variants, but were unable to find any missense mutation or association of common $K L F 11$ variants in late-onset Type2 diabetes in 1818 Japanese subjects [26].

In the present study, the minimal promoter region identified in this study, 5'UTR, coding region, 3'UTR, and flanking introns were screened for mutations in unrelated Japanese subjects with 182 early-onset and 96 late-onset T2DM patients. Our analysis revealed a novel missense mutation, R29Q $(\mathrm{G}>\mathrm{A})$, in exon 2 in two early-onset type 2 diabetes patients and three lateonset T2DM patients in the heterozygous state and $\mathrm{S} 124 \mathrm{~F}$ in exon 3 in one early-onset type 2 diabetes patient, but none of the A347S, T220M, Q62R, and promoter variant $-1659 \mathrm{G}>\mathrm{C}$ mutations previously 
identified in Northern Europeans in KLF11.

We examined about $13 \mathrm{~kb}$ covering the entire coding region of KLF11 and identified a total of 19 genetic variations including 6 novel variants. We defined haplotypes based on the LD pattern estimated using the 16 most frequent SNPs, the frequencies of which were more than $10 \%$, and performed an association study with T2DM. No association of KLF11 variants with T2DM was found and no haplotypes were found to show susceptibility to T2DM. We examined one variant, rs 4073397 , located $21 \mathrm{~kb}$ upstream from the coding region and outside of the LD block of the KLF11 region, that shows a marginal association with T2DM in Japanese [26], but we could not replicate the association in this study with power similar to that of the former report $(P=0.268$ and 0.576 for allele and genotype analysis, respectively; OR 1.2; RAF 0.5 ; $\alpha=0.05 ; 1-\beta=63.9 \%$ ).

We searched for consensus sequences of transcription factor binding sites in the promoter region by using TFSEARCH. As shown in Fig. 6, no TATA-box and ten Sp1 binding sites were found, but there were no differences in haplotype frequencies of the KLF11 promoter region between T2DM patients and controls. It is of interest that one of the promoter polymorphisms, SNP-4, is located at the sixth Sp1 binding site from the transcription start site and that this binding site is not incorporated in one of the major haplotypes, but significantly reduced promoter activity of this haplotype was not detected by promoter assay in MIN6$\mathrm{m} 9$ cells. One of the major haplotypes comprising all of the minor alleles showed the highest transcriptional activity with the longest and the second longest constructs. No association of the haplotype with occurrence of T2DM was found, but the findings are inconclusive due to the low statistical power of this study. In any case, the effect of the KLF11 expression level itself on the onset of type 2 diabetes should be slight, if any at all.

RT-PCR demonstrated endogenous KLF11 mRNA expression in whole rat pancreas, human pancreas, and mouse MIN6-m9 cells (data not shown). We therefore examined whether the KLF11 mutant affects transcriptional regulation of the human insulin gene. We found, contrary to Neve's report [17], that wild-type KLF11 inhibited insulin promoter activity as Niu et al. reported [18], but no difference in activity between wild and KLF11 mutants was found. Inhibition by wild-type KLF11 was similar in the three beta cell lines, INS-1E, beta-TC3 in the previous study, and MIN6-m9 in this study, indicating stable performance of KLF11 inhibition of insulin promoter activity in rodent beta cells.

KLF11 is involved in the TGF- $\beta$ pathway, which plays a critical role in the development and homeostasis of exocrine and endocrine pancreas via Smad signaling $[16,27]$. KLF11 may affect pancreatic beta cell function by modulating the expression of free radical scavengers such as superoxide dismutase (SOD) 2 and catalase1, recently identified as KLF11 target genes [10]. Oxidative stress is generally believed to be involved in the progression of pancreatic beta cell dysfunction found in T2DM $[28,29]$. Since a decreased expression level of these antioxidant enzyme genes might contribute to the occurrence of type 2 diabetes, we examined the effects of the KLF11 R29Q and $\mathrm{S} 124 \mathrm{~F}$ variants on the expression levels of these target genes.

We then examined whether or not KLF11 mutants affect transcriptional regulation of the catalase 1 and Smad7 genes. A significant but small difference in promoter activity between wild-type and R29Q mutant was found in catalase 1 only. R29Q mutation is located 12 amino acids upstream of SID (mSin3A interaction domain)/R1 domain, which determines repression activity of KLF11 [10, 30-33]. This mutant of KLF11, although showing somewhat different activities in the catalase1 promoter, showed similar transcriptional activity compared with wild-type KLF11. Although it is inconclusive whether or not R29Q mutation contributes to the development of type 2 diabetes because of the small sample number in this study (Fisher's $P$ value $=0.245$ ), our results suggest that the mutation does not contribute to the development of type 2 diabetes through alteration of the expression level of these target genes. No unusual clinical characteristics were found in subjects with R29Q mutation.

$\mathrm{S} 124 \mathrm{~F}$ mutation is located between the SID/R1 and $\mathrm{R} 2$ domain, and is not conserved among rat, mouse, and human, i.e., proline for rat and mouse and serine for human. Similar data were obtained from S124F mutant of KLF11, which showed somewhat different activities in insulin and catalase 1 promoters and similar transcriptional activity compared with wild-type KLF11, suggesting little biological effect. No useful clinical information was available for the patient with S124F mutant.

In this study, we focused on the effects of KLF11 on 
beta cell function. In addition, the caveolin-1 gene, which is highly expressed in adipose tissue, is repressed by KLF11 in a cholesterol-dependent manner [34]. The findings that caveolin-1 binding to the insulin receptor stimulates both kinase activity and recruitment of the insulin receptor to lipid rafts at the plasma membrane, and that insulin receptor mutations impairing calveolin binding result in T2DM [35] indicate that caveolin-1 is essential for insulin signaling and suggest that KLF11 might affect insulin sensitivity as well.

In conclusion, we identified two novel missense variants of KLF11 and the minimal promoter region of $K L F 11$, but neither of the variants nor the haplotypes identified in this study was associated with the occurrence of type 2 diabetes in Japanese, although the findings are inconclusive due to the low statistical power of the study. Further investigation with a larger sample number is required to determine the magnitude of the contribution of the R29Q and S124F mutations to the development of diabetes and the role of KLF11 in normal pancreatic $\beta$-cell function. Identification of the minimal promoter region of KLF11 should be useful in further elucidation of its transcriptional regulation mechanism.

\section{Acknowledgments}

We thank Tsuchida H, Yokoyama K, Kawada J, Uda I, and Ibe Y for technical assistance. Grants: This work was supported by a Health and Labor Science Research Grant for research on Human Genome and Tissue Engineering from the Japanese Ministry of Health, Labor and Welfare, a Grant-in-Aid for Scientific Research from the Japanese Ministry of Science, Education, Sports, Culture and Technology, and a New Energy and Industrial Technology Development Organization Grant.

\section{References}

1. Bieker JJ (2001) Kruppel-like factors: three fingers in many pies. J Biol Chem 276: 34355-34358.

2. Lomberk G, Urrutia R (2005) The family feud: turning off Sp1 by Sp1-like KLF proteins. Biochem J 392: 111.

3. Turner J, Crossley M (1999) Mammalian Kruppel-like transcription factors: more than just a pretty finger. Trends Biochem Sci 24: 236-240.

4. Cook T, Gebelein B, Mesa K, Mladek A, Urrutia R (1998) Molecular cloning and characterization of TIEG2 reveals a new subfamily of transforming growth factor-beta-inducible Sp1-like zinc finger-encoding genes involved in the regulation of cell growth. $J$ Biol Chem 273: 25929-25936.

5. Kaczynski J, Cook T, Urrutia R (2003) Sp1- and Kruppel-like transcription factors. Genome Biol 4: 206.

6. Black AR, Black JD, Azizkhan-Clifford J (2001) Sp1 and kruppel-like factor family of transcription factors in cell growth regulation and cancer. J Cell Physiol 188: 143-160.

7. Asano H, Li XS, Stamatoyannopoulos G (1999) FKLF, a novel Kruppel-like factor that activates human embryonic and fetal beta-like globin genes. Mol Cell Biol 19: 3571-3579.

8. Ou XM, Chen K, Shih JC (2004) Dual functions of transcription factors, transforming growth factor-betainducible early gene (TIEG). 2 and Sp3, are mediated by CACCC element and Sp1 sites of human monoamine oxidase (MAO) B gene. J Biol Chem 279: 2102121028.

9. Scohy S, Gabant P, Van Reeth T, Hertveldt V, Dreze
PL, Van Vooren P, Riviere M, Szpirer J, Szpirer C (2000) Identification of KLF13 and KLF14 (SP6), novel members of the SP/XKLF transcription factor family. Genomics 70: 93-101.

10. Fernandez-Zapico ME, Mladek A, Ellenrieder V, Folch-Puy E, Miller L, Urrutia R (2003) An mSin3A interaction domain links the transcriptional activity of KLF11 with its role in growth regulation. EMBO J 22: 4748-4758.

11. Robertson RP, Harmon J, Tran PO, Poitout V (2004) Beta-cell glucose toxicity, lipotoxicity, and chronic oxidative stress in type 2 diabetes. Diabetes 53: Suppl $1 \mathrm{~S} 119-124$.

12. Massague J, Blain SW, Lo RS (2000) TGFbeta signaling in growth control, cancer, and heritable disorders. Cell 103: 295-309.

13. Ellenrieder V, Buck A, Harth A, Jungert K, Buchholz M, Adler G, Urrutia R, Gress TM (2004) KLF11 mediates a critical mechanism in TGF-beta signaling that is inactivated by Erk-MAPK in pancreatic cancer cells. Gastroenterology 127: 607-620.

14. Kim SK, Hebrok M (2001) Intercellular signals regulating pancreas development and function. Genes Dev 15: 111-127.

15. Sanvito F, Herrera PL, Huarte J, Nichols A, Montesano R, Orci L, Vassalli JD (1994) TGF-beta 1 influences the relative development of the exocrine and endocrine pancreas in vitro. Development 120: 3451-3462.

16. Smart NG, Apelqvist AA, Gu X, Harmon EB, Topper JN, MacDonald RJ, Kim SK (2006) Conditional expression of Smad 7 in pancreatic $\beta$ cells disrupts TGF- $\beta$ 
signaling and induces reversible diabetes. Plos Biol 4: e39.

17. Neve B, Fernandez-Zapico ME, Ashkenazi-Katalan V, Dina C, Hamid YH, Joly E, Vaillant E, Benmezroua Y, Durand E, Bakaher N, Delannoy V, Vaxillaire M, Cook T, Dallinga-Thie GM, Jansen H, Charles MA, Clement K, Galan P, Hercberg S, Helbecque N, Charpentier G, Prentki M, Hansen T, Pedersen O, Urrutia R, Melloul D, Froguel P (2005) Role of transcription factor KLF11 and its diabetes-associated gene variants in pancreatic beta cell function. Proc Natl Acad Sci USA 102: 4807-4812.

18. Niu X, Perakakis N, Laubner K, Limbert C, Stahl T, Brendel MD, Bretzel RG, Seufert J, Path G (2007) Human Kruppel-like factor 11 inhibits human proinsulin promoter activity in pancreatic beta cells. Diabetologia 50:1433-1441.

19. Gutiérrez-Aguilar R, Froguel P, Hamid YH, Benmezroua Y, Jørgensen T, Borch-Johnsen K, Hansen T, Pedersen O, Neve B (2008) Genetic analysis of KLF11 variants in 5,864 danish individuals; potential effect on insulin resistance and modified signal transducer and activator of transcription-3 binding by promoter variant 1659G>C. J Clin Endocrinol Metab 93: 3128-3135.

20. Kuzuya T, Nakagawa S, Satoh J, Kanazawa Y, Iwamoto Y, Kobayashi M, Nanjo K, Sasaki A, Seino Y, Ito C, Shima K, Nonaka K, Kadowaki T (2002) Report of the Committee on the classification and diagnostic criteria of diabetes mellitus. Diabetes Res Clin Pract 55: 6585.

21. Minami K, Yano H, Miki T, Nagashima K, Wang CZ, Tanaka H, Miyazaki JI, Seino S (2000) Insulin secretion and differential gene expression in glucose-responsive and -unresponsive MIN6 sublines. Am J Physiol Endocrinol Metab 279: E773-781.

22. Florez JC, Saxena R, Winckler W, Burtt NP, Almgren P, Bengtsson Bostrom K, Tuomi T, Gaudet D, Ardlie KG, Daly MJ, Altshuler D, Hirschhorn JN, Groop L (2006) The Kruppel-like factor 11 (KLF11) Q62R polymorphism is not associated with type 2 diabetes in 8,676 people. Diabetes 55: 3620-3624.

23. Ma L, Hanson RL, Que LN, Mack JL, Franks PW, Infante AM, Kobes S, Bogardus C, Baier LJ (2008) Association anlysis of KLF11 variants with type 2 diabetes in Pima Indians. J Clin Endocrinol Metab 93: 3644-3649.

24. Fukushima M, Suzuki H, Seino Y (2004) Insulin secretion capacity in the development from normal glucose tolerance to type 2 diabetes. Diabetes Res Clin Pract 66: Suppl $1 \mathrm{~S} 37-43$.
25. Matsuoka K (2000) Genetic and environmental interaction in Japanese type 2 diabetics. Diabetes Res Clin Pract 50: Suppl 2 S17-22.

26. Tanahashi T, Shinohara K, Keshavarz P. Yamaguchi Y, Miyawaki K, Kunika K, Moritani M, Nakamura N, Yoshikawa T, Shiota H, Inoue H, Itakura M (2008) The association of genetic variants in Kruppel-like factor 11 and Type 2 diabetes in the Japanese population. Diabetic Medicine 25: 19-26.

27. Cook T, Urrutia R (2000) TIEG proteins join the Smads as TGF-beta-regulated transcription factors that control pancreatic cell growth. Am J Physiol Gastrointest Liver Physiol 278: G513-521.

28. Rehman A, Nourooz-Zadeh J, Moller W, Tritschler H, Pereira P, Halliwell B (1999) Increased oxidative damage to all DNA bases in patients with type II diabetes mellitus. FEBS Lett 448: 120-122.

29. Sakuaba H, Mizukami H, Yagihashi N, Wada R, Hanyu C, Yagihashi S (2002) Reduced $\beta$ cell mass and expression of oxidative stress related DNA damage in the islet of Japanese type II diabetic patients. Diabetologia 45: 85-96.

30. Ellenrieder V, Zhang JS, Kaczynski J, Urrutia R (2002) Signaling disrupts $\mathrm{mSin} 3 \mathrm{~A}$ binding to the Mad1-like Sin3-interacting domain of TIEG2, an Sp1-like repressor. EMBO J 21: 2451-2460.

31. Cook T, Gebelein B, Belal M, Mesa K, Urrutia R (1999) Three conserved transcriptional repressor domains are a defining feature of the TIEG subfamily of Sp1-like zinc finger proteins. J Biol Chem 274: 29500-29504.

32. Hassig CA, Fleischer TC, Billin AN, Schreiber SL, Ayer DE (1997) Histone deacetylase activity is required for full transcriptional repression by $\mathrm{mSin} 3 \mathrm{~A}$. Cell 89 341-347.

33. Zhang JS, Moncrieffe MC, Kaczynski J, Ellenrieder V, Prendergast FG, Urrutia R (2001) A conserved alphahelical motif mediates the interaction of Sp1-like transcriptional repressors with the corepressor $\mathrm{mSin} 3 \mathrm{~A}$. Mol Cell Biol 21: 5041-5049.

34. Cao S, Fernandez-Zapico ME, Jin D, Puri V, Cook TA, Lerman LO, Zhu XY, Urrutia R, Shah V (2005) KLF11-mediated repression antagonizes SP1/sterolresponsive Element-binding protein-induced transcriptional activation of caveolin-1 in response to cholesterol signaling. J Biol chem 280: 1901-1910.

35. Cohen AW, Combs TP, Scherer PE (2003) Role of caveolin and caveolae in insulin signaling and diabetes. Am J Physiol Endocrinol Metab 285: E1151-E1160. 